\title{
Arabic Language Test in the Perspective of Competency- Based Curriculum for Students of Madrasah Aliyah Negeri 3 Malang
}

\section{Muhammad Qodri}

\section{Universitas Islam Negeri (UIN) Sulthan Thaha Saifuddin Jambi, Indonesia} e-mail : mqodri87@gmail.com

\begin{abstract} school exam in the curriculum based on proficiency. The data were collected in the manner of documents and interviews. The results of this research are in harmony between the items of the final Arabic language test questions for students of the Madrasah Aliyah 3 Malang in the academic year 2011/2012 with the curriculum on the basis of competence, which contains: Reading skill questions are also suited to normative and basic competence, although these items do not contain items of phonics questions in language questions and listening, speaking and writing items in language skills questions.
\end{abstract}

The purpose of this research is to describe the items of the final Arabic language test questions for students of the Government Islamic Secondary School 3 Malang in the light of the proficiency based curriculum (KBK). This research is the type of desk research on the descriptive analytical approach qualitative approach. The data sources in this research are in the form of Arabic language question documents for the final

Keyword

Arabic Language Test; Competency-Based Curriculum; Final School Test Questions

$$
\begin{aligned}
& \text { يهدف هذا البحث إلى وصف بنود أسئلة اختبار اللغة العربية النهائي المدرسي }
\end{aligned}
$$

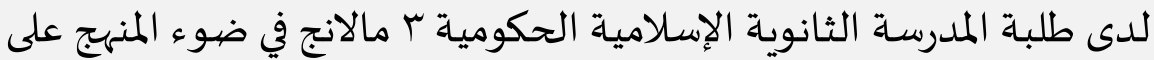

$$
\begin{aligned}
& \text { أساس الكفاءة (KBK). وهذا البحث من نوع البحث المكتبي على المنهج }
\end{aligned}
$$

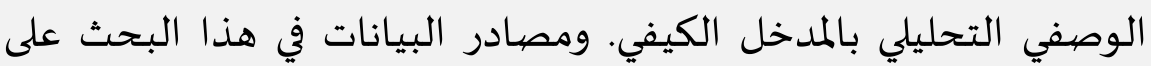

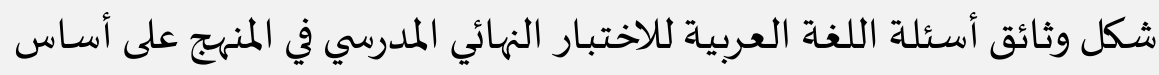

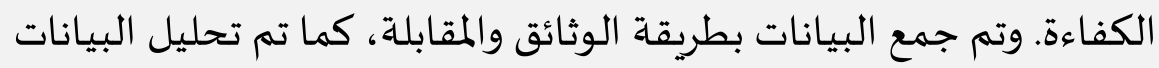

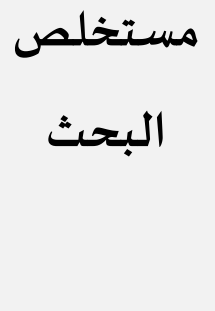


بطريقة تحليل المضمون مع الخطوات التي اقترحها كريفندورف على أن تحليل المضمون تضمنت خطوات هي قراءة الوثائق، وتقرير الوحدات، وأخذ التذاتئ

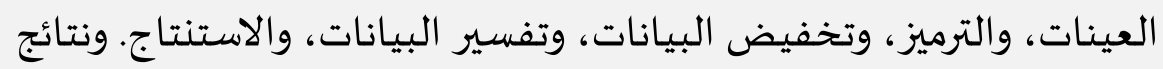
هذا البحث هي هناك تناسب بين بنود أسئلة اختبار اللغة العربية النهائي

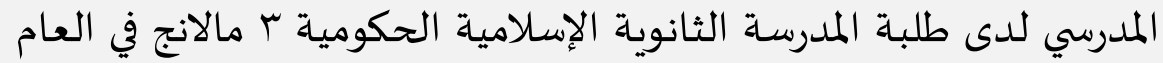

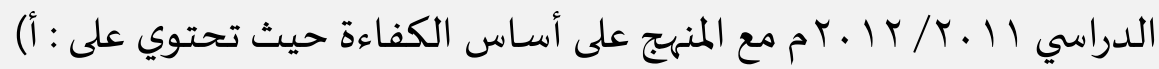

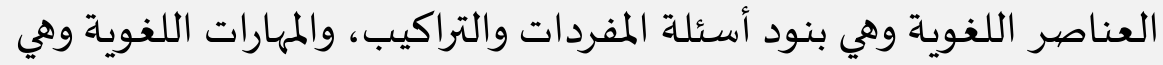
بنود أسئلة مهارة القراءة، كما تناسب البنود الكفاءة المعيارية والكفاءة

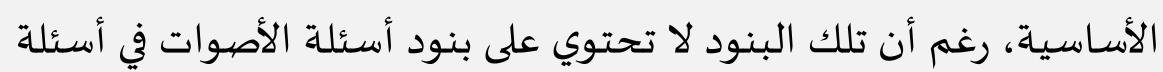

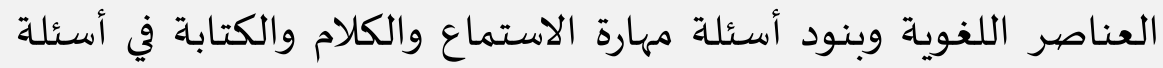

$$
\text { المهارات اللغوية. }
$$

اختبار اللغة العربية؛ المنهجج على أساس الكفاءة؛ أسئلة الاختبار النهائي كلمات المدرسي أسـاسية

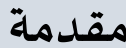

التقويم التربوي هو أداة المبربين للانتقال بالعملية التعليمية مما هو قائم إلى ما يينبغي أن يكون. فهو الأسلوب العلمي والعملي الذي يتم من خلاله تشخيص دقيق للواقع التربوي. واختبار لمدى كفاءة الوسائل المستخدمة والاستفادة من ذلك في تعديل وتوجيه المسار التربوي نحو تحقيق الأهداف على نحو أفضل(خليل, 11 . ץ: 1). فالتقويم وسيلة للتشخيص لمعرفة مستويات المتعلمين وبالتالي تطويع المادة العلمية وأساليب تدريسها لتناسب مع كل متعلم. التقويم جزء مركب لا يتجزأ من العملية التربوية والتعليمية. تتضمن العملية التربوية والتعليمية كثيرا من المحاور الأسساسية التي تحقق لها النجاح اللازم لتنشئة الأجيال البشرية تنشئة صالحة فاعلة في مجتمعها محققة لذاتها ولغيرها التقدم والرخاء والازدهار. وتبدأ هذه المحاور بتحديد أهداف التعليم، والتخطيط له، ثم الوسائل وأوجه المناشط التي يتبعها المعلم والمدرسة لتحقيق هذه الأهداف، ثم أخيرا تأتي عملية التقويم لما تم تنفيذه في ضوء الأهداف، لتحديد المراحل التالية اللازمة لاستمرارية التعليم. 
الاختبار وسيلة من وسائل التقويم التربوية الشائعة، الاختبار لدياء مكان ودور واضح مرتبط بالتعليم، وكذلك جزء لا يتجزأ منه. في نظرية الإعداد والتخطيط للتعليم، يوصف التعليم بأنه عملية التي تتكون من ثلاثة مكونات رئيسية لا يمكن فصلها بعضها من بعض. المكونات الثلاثة هي أهداف التعليم، وتنفيذ التعليم، وتقييم نتائج التعليم (Djiwandono, 2008: 2) تقييم نتائج التعليم هو مكون أخير في سلسلة من مكونات تنفيذ التدريس، مكون التقييم له ارتباط وثيق بالمكونات التي سبقته، المكون الثاني (تطبيق التعليم) خاصة. من خلال مكون التقييم، يمكن معرفة النجاح أو الفشل، ومما اكتسبه من خلال تنفيذ التدريس. في سياق تعليم اللغة العربية، الهدف من تقييم المواد اللغة العربية في المدارس للحصيول على على اهلى صورة لموقف الطلاب في إتقان أربعة جوانب من مهارات اللغوية وهي مهارة الاستماع، والكلام،

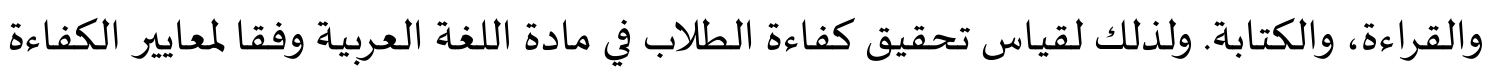
المحددة، من الضروري تقييم نتائج التعلم للطلاب في نهاية وحدة التعليم. يتم تقييم نتائج التعلم

$$
\text { من خلال امتحانات المدارس. }
$$

أما الهدف من تطبيق الاختبار النهائي المدرسي للمدارس الإسلامية لتعزيز خصائص المدارس

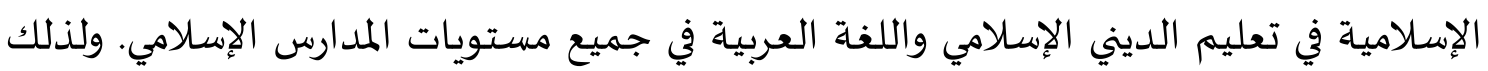

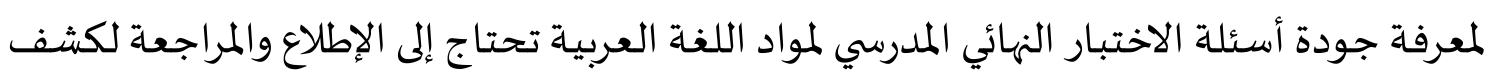
جودة أسئلة اللغة العربية مختبرة. هناك كثير من الدراسات والبحوث عن تحليل بنود أسئلة اختبار اللغة العربية، التي تتعلق

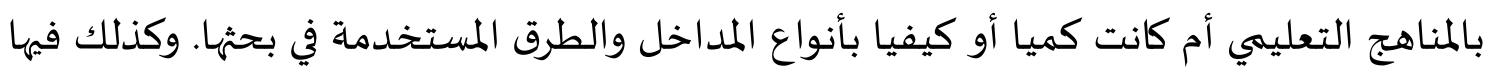
الدراسات والبحوث التي تتعلق بموضوع البحث الذي بحثه الباحث. ولذلك عرض الباحث البحوث

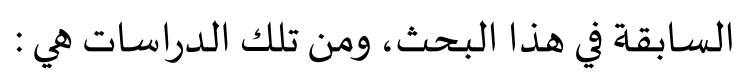

ا- البحث الذي قام به حسن عبد الرباح علي الحسنات تحت العنوان "تحليل أسئلة تقييم في

كتاب المدرسي العربي من الصف الثامن في الأردن على أساس تصنيف بلوم في فئات البعد البعد

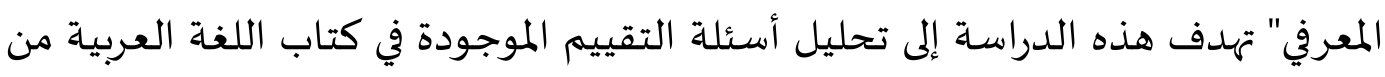

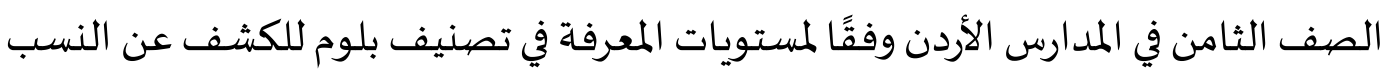

المئوية لتوزيع هذه الأسئلة في هذا التصنيف. النتائج هذا البحث : أ) ركزت الأسئلة في الكتب

Please cite this article as Muhammad Qodri. (2019). Arabic Language Test in the Perspective of

Competency-Based Curriculum for Students of Madrasah Aliyah Negeri 3 Malang. Izdihār : Journal of Arabic Language Teaching, Linguistics, and Literature, 2(2), 115-134. DOI: 
المدرسي أكثرها على مستويات التفكير المنخفضية. ب) وجود الاختلاف بين بياني والنسب

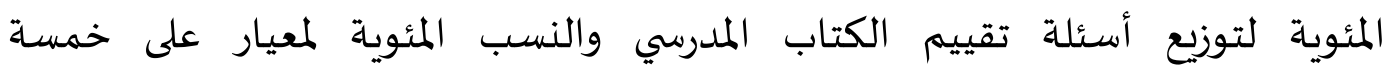
مستويات(حسن \& القايد, . 199:10 1).

r- البحث الذي قام باه محمود سليمان بني عبد الرحمن تحت العنوان "تحليل أسئلة اللغة

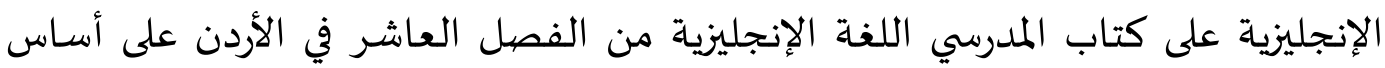
تصنيف بلوم المعدل". تهدف هذه الدراسة إلى تحليل أنواع ومستويات الأسئلة المتوفرة في الكتاب المدرسي اللغة الإنجلزية للصف العاشر التي استخدامها في الأردن خلال العام

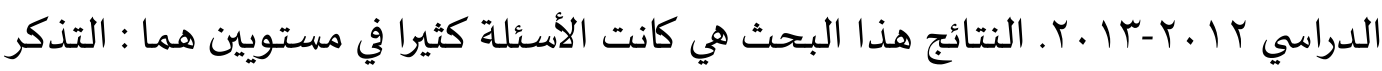

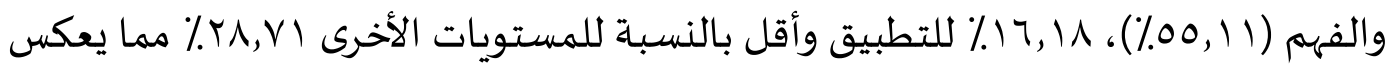
رجحان مسألة المستوى المنخفض في الكتابين المدرسيين. أظهرت النتائج أن الفرق لصالح

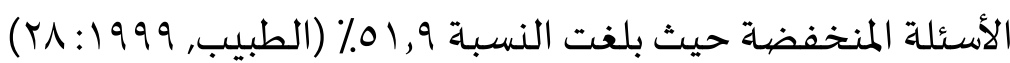
r- البحث الذي قامت به رزقا أنوغراه تحت العنوان: "تقويم بنود أسئلة في اختبار اللغة العربية

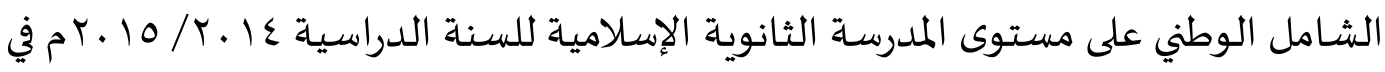

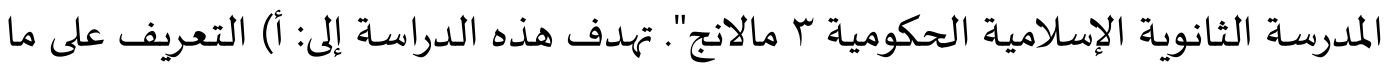

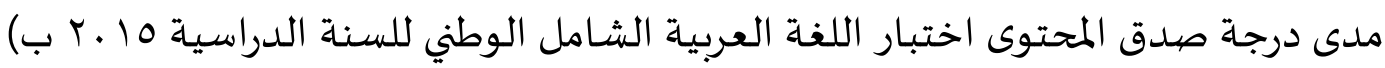
التعريف على درجة صدق والثبات بنود أسئلة في اختبار اللغة العربية الشامل الوطني للسنة

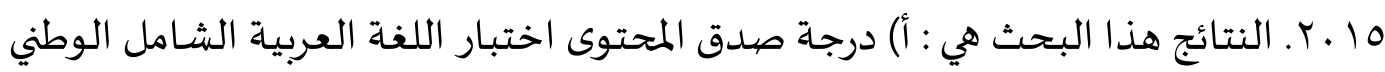
للسنة 10 10 هي جيدة من ناحية المواد لتناسب بعض الأسئلة بالمعايير مقررة من وزارة الشؤون الدينية للمتخرجين. ولكن مضمون هذه الأسئلة لم يكن بالتساوي بين عناصر اللغة ومهارات اللغة العبية وكانت بنود أسئلة هذ الاختبار تتكلم كثيرا عن القوائد اللغوية. ب)

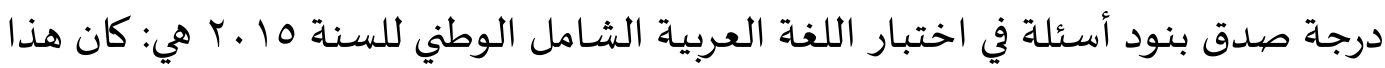

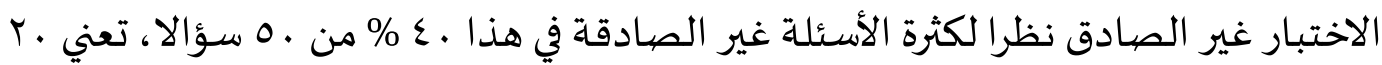

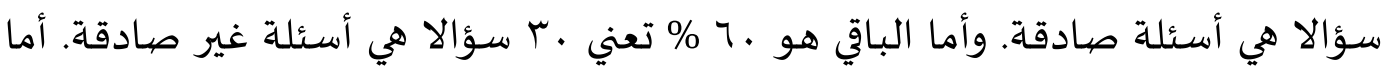

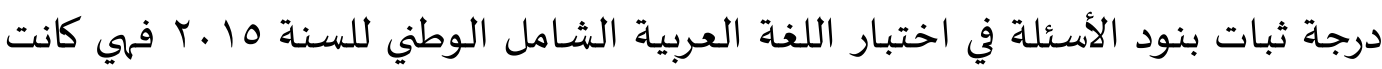
النتيجة (r statistik/Spearman Brown) أكبر من نتيجة (r Tabel)، وتلك النتيجة تدل على وجود 
الاتصال على شكل ملحوظ بين X و X. إذا، ذلك التحليل يدل على هذ الاختبار له درجة

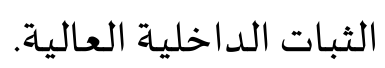

رأى الباحث أن الدراسات السابقة تختلف عن الدراسة التي بحثه الباحث كلّها من حيث الخلفيات واختلاف الظروف وهيئة مجتمع البحث على سبيل الإجمال ولا يبحث الخاص عن الاختبار اللغة العربية في ضوء المنهج على أساس الكفاءة. رغم وجود بعض الاختلافات في الأهداف أو المناهج، وإن تنوع الدراسات السابقات وتناولها جوانب كثيرة يكسب الباحث سعة في الإطلاع بكل الجوانب المتعلقة بالاختبار اللغة العربية في ضوء المنهج على أساس الكفاءة.

من خلال الملاحظة على وثائق أسئلة اللغة العربية للاختبار النهائي المدرسي لدى طلبة

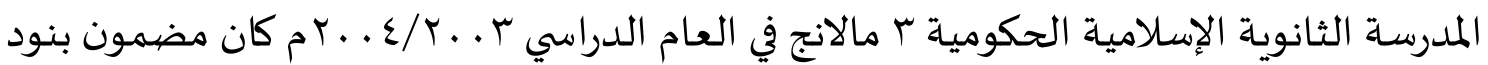
الأسئلة لهذا الاختبار غير موازنة بين عناصر اللغة ومهاراتها. وكانت بنود أسئلة عناصر اللغة تركز كثيرا عن التراكيب اللغوية، وبقية من الأسئلة عن المفردات. كما أن بنود أسئلة مهارات اللغوية تهتم كثيرا بمهارة القراءة دون غيرها (ملاحظة 17 أغسطس (1) 1.) وبذلك، أصبحت بنود الأسئلة الموجودة لا تحتوي على الأهداف التعليمية الشاملة على العناصر اللغوية المهارات اللغوية المتعلقة بالموضوع الدراسي. واستنبط الباحث أن أسئلة الأساسية في هذا البحث هي : هل بنود أسئلة اللغة

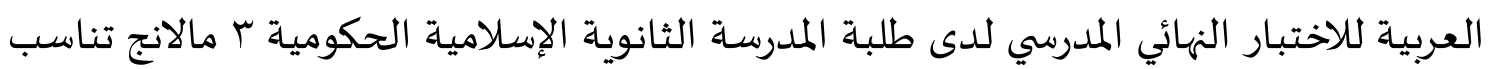

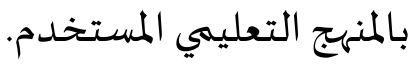

\section{نظريات}

\section{أ- التقويم التربوي وما يتعلق به}

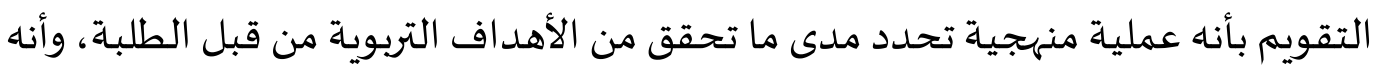
يتضمن وصفا كميا وكيفيا، بالإضافة إلى إصدار حكم على القيمة. (مصطفى نمر، 1. .ب: Y I) ويرى صالح علام أن التقويم هو عملية منهجية تتطلب جمع بيانات موضوعية ومعلومات صادقة من مصادر متعددة باستخدام أدوات قياس متنوعة في ضوء أهداف محددة بغرض التوصل إلى

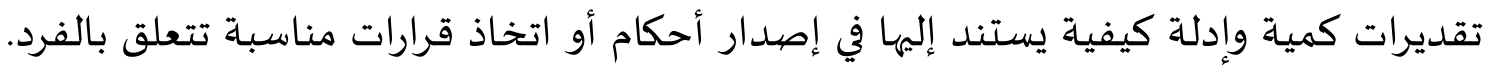

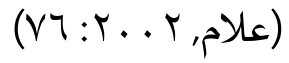

Please cite this article as Muhammad Qodri. (2019). Arabic Language Test in the Perspective of Competency-Based Curriculum for Students of Madrasah Aliyah Negeri 3 Malang. Izdihār : Journal of Arabic Language Teaching, Linguistics, and Literature, 2(2), 115-134. DOI: 
فالتقويم التربوي له تعريفات عدة، فقد عرفه الحريري بأنه عملية إصلاح وتعديل، وهو العملية التي يتم من خلالها تشخيص جوانب القصور في العملية التربوية، ووصف العلاج اللازم لتعديل جوانب الضعف، وهو العملية التي يتم من خلالها اكتشاف مواطن القوة في العملية

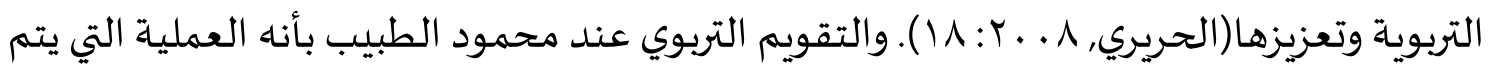
بها إصدار حكم على مدى وصول العملية التعليمية إلى أهدافها ومدى تحقيقها لأغراضها، والعمل على كشف نواحي النقص في العملية التربوية في أثناء سيرها. ويعرف التقويم التربوي بأنه العملية التي تستخدم فهها نتائج عملية القياس الكمي والكيفي،

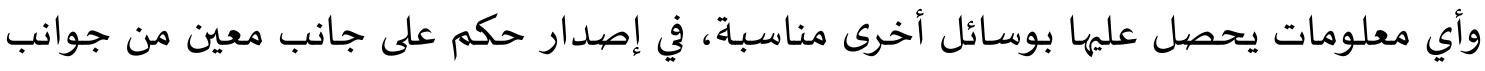
شخصية المتعلم، أو على جانب معين من جوانب المنهج، واتخاذ قرارات بشأن هذا الحكم بقصيد

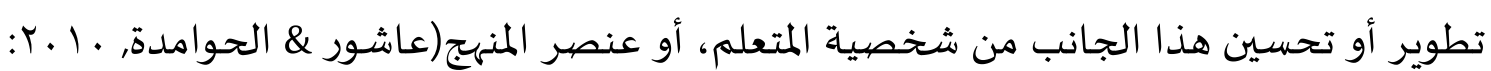

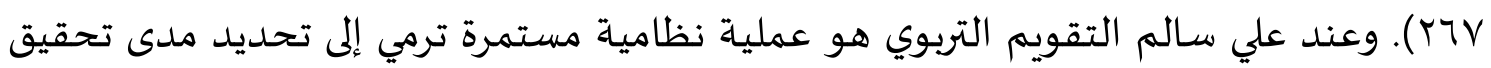
العملية التربوية لأهدافها، وتحديد نواحي القوة وتعزيزها وتحديد نواحي الضعف وعلاجها في كل

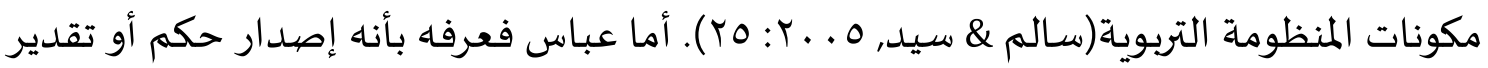

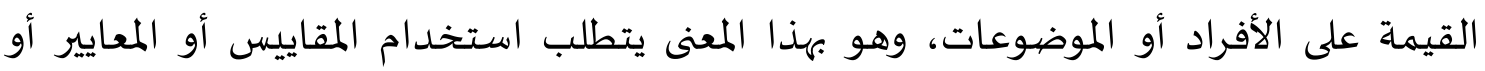
المحكات لتقدير قيمة هذه النتيجة (عباس, 1997 19 19 ). من التعريفات السابقة، التقويم التربوي بأنه عملية منظمة لجمع وتحليل المعلومات بغرض التهات تحديد درجة تحقيق الأهداف التربوية واتخاذ القرارات بشأنها لمعالجة جوانب الضعف وتوفير النمو السليم المتكامل من خلال إعادة تنظيم البيئة التربوية واثرائها. يتصف التقويم بشمولية نظرة إلى مكونات العملية التربوية ويبحث كذلك عن الأسباب التي تؤدي إلى ضعفها أو قوتها من خلال نظرته الشمولية هذه. ومع ذلك فإن أهداف التقويم تركز على مدانى المكونات الجزئية للعملية التربوية والتعليمية، لكنها في الأخير تربط بين هذه الجزئيات لتكون حكما عاما وشموليا على العملية التربوية والتعليمية برمتها. وأهداف التقويم منها : الكشف عن مدى تحقيق الأهداف التربوية والتعليمية المرسومة سلفا والجوانب التي تحتاج إلى تطوير أو تعديل أو

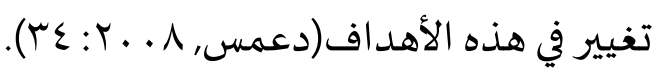
من الأهداف المذكورة، أن التقويم بأنه مهم جدا لترقية جودة التعليم والتعلم، بالتقويم المعلم يستطيع أن يرى الأهداف المحصولة لنجاح الطلاب بعد اشتراكهم في عملية التعليم والتعلم، 
وكذلك يقوم المعلم التشخيص والعلاج لجوانب الضعف والرقي بجوانب القوة من ناحية الطريقة المستخدمة أو المواد المدروسة والأشياء الأخرى التي تأثر كثيرا لنجاح التعليم والتعلم.

\section{ب- اللمحة عن الاختبار

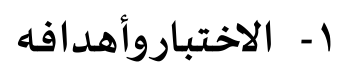

الاختبار هو مجموعة من المفردات "الأسئلة" التي تعطي للطالب للإجابة عنها شفويا أو تحريريا وقد تكون موضوعية أو مقالية أو رسوما أو أشكالا تستخدم للمقارنة والقياس.

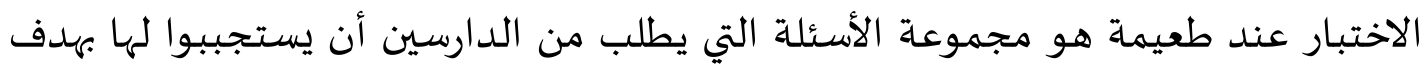
قياس مستواهم في مهارة لغوية ومعينة وبيان مدى تقدماه فيها ومقارنته بزملائه (طعيمة, 91919 19: (Y VV ) الاختبار بأنه تمرين مكتوب أو شفوي أو تطبيق ينجزه المتعلم خلال امتحان أو مباراة

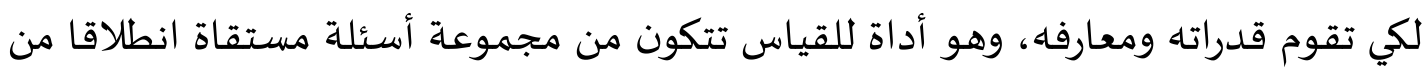

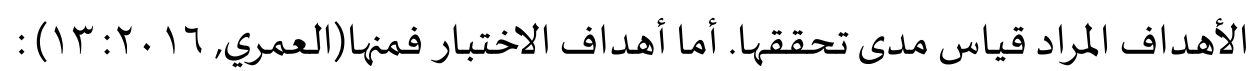
أهد اف ما قبل التدريس

لتحديد إلى أي مدى يمتلك الطلاب المهارات والقدرات السابقة اللازمة للبدء في التدريس، ويتم ذلك بتنفيذ اختبار قبلي لتحديد درجاة الاستعداد عند الطلاب ويغطي هذا الاختبار

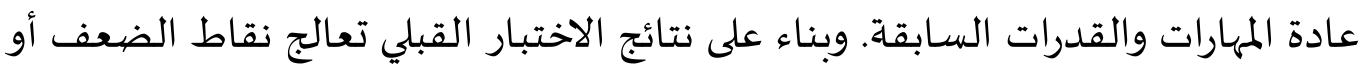

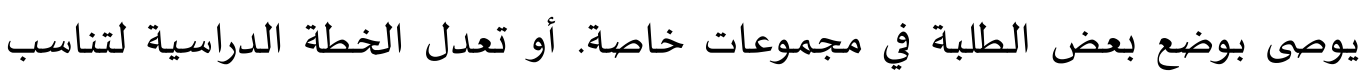

$$
\text { مستوى الطلاب. }
$$

لتحديد جوانب المادة الدراسية التي يتقدم فيها الطلاب بشكل مناسب والجوانب التي

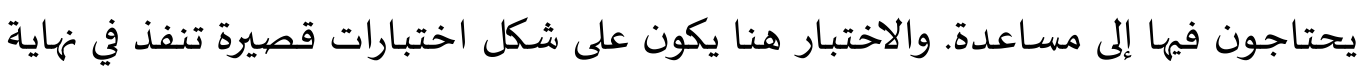

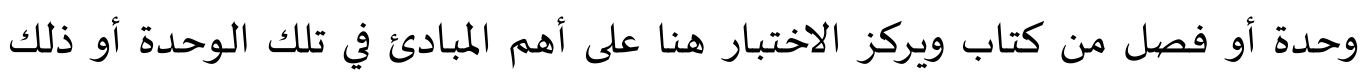

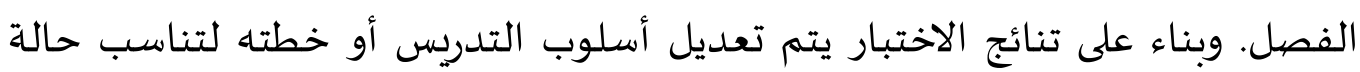

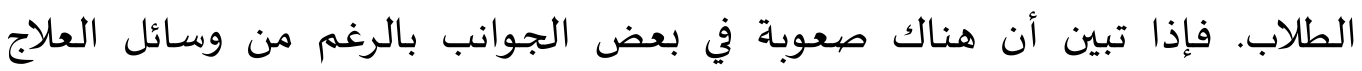


والتعديلات نلجأ إلى اختبار تشخيصي لتحديد أسباب الضعف الحقيقية وليس فقط نقاط الضعف

$$
\text { أهداف ما بعد التدريس }
$$

للتحقق من مدى امتلاك الطلاب للمهارات والقدرات اللازمة للانتقال إلى صف أعلى أو المنهاج الذي يليه أو لإعطاء كل طالب العلامة أو الدرجة التي يستحقها في المادة الدراسية. والاختبار هنا يكون شـاملا للمنهاج وممثلا بعينة مناسبة من الفقرات أو الأسئلة بحيث

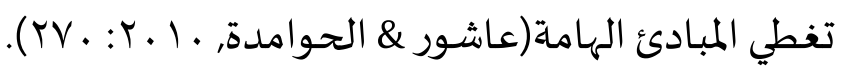

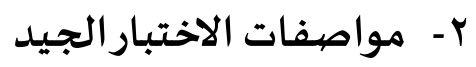

هناك اختبارات جيدة متقنة في هدفها وشكلها ومضمونها لأنها التزمت بمواصفات

$$
\text { الاختبار الجيد. وهذه المواصفات فيما يلي : }
$$

أ) الصدق : ويقصد به أن الاختبار يقيس ما وضع لقياسـه. وعلى هذا الاسـاس فإن اختبار النحو الذي يمتلئ بكلمات صعبة تتطلب فهم الطالب لها أولا لا يعتبر اختبارا صادقا.

$$
\text { لأناه يقيس تعرف المفردات إلى جانب القواعد النحوية }
$$

ب) الثبات : يقصيد باه أن الاختبار يعطي نفس النتائج لنفس المجموعة من الأفراد إذا ما طبق مرة أخرى في نفس الظروف وبعد مسافة قصيرة. وعلى هذا الأسـاس فإن الاختبار الذي يتغير وضع الطلاب كثيرا بعد إعادة تطبيقه لا يعتبر ثابتا. ج) الموضوعية : يقصد بها عدم تأثير شخصية المصحح على وضيع أو تقدير علامات الطلاب في الاختبار. ومما سـاعد على تحقيق الموضوعية أن يفهم الطلاب تعليمات الاختبار بدقة وأن يكون هناك تفسير واحدة للأسئلة والإجابة المطلوبة مناه فضلا عن توفير الظروف المادية والنفسية للطلاب لأداء الاختبار. د) سهولة التطبيق : تتأثر عملية التطبيق الاختبار بعوامل متعددة، منها ما يتصل بالاختبار وما يتميز باء من خصائص، ومنها ما يتصل بمن يعطي الاختبار، ومنها ما يتصل بالتلاميذ الذين يطبق عليهم الاختبار. لذلك يجب على المعلم أن يراعي الجو النفسي والاجتماعي المناسب للتلاميذ، بحيث يمكنهم من أداء الاختبار بدقة. 
ه) الاقتصياد : يشـمل الاقتصياد في الوقت والجهد والمال والفريق الذي يقوم بالتصحيح. فالحكم على الزمان الذي يستغرقه إجراء الاختبار يكون في أغلب الأحيان غير سليم وقد يفوت ذلك حتى على أكثر واضعي الاختبارات حنكة وخبرة وخاصة إذا كان الاختبار

$$
\text { و) درجة التمييز يحتوي على اختبارات فرعية (محمد, } 911 \text { (: سه) }
$$

ويقصد باه أن الاختبار يستطيع أن يبرز الفروق بين الطلاب فيبين لنا الأقوياء من الضعاف. ويتطلب هذا أن يكون هناك مدى واسع بين السهل والصعب من الأسئلة بحيث يؤدي هذا إلى توزيع معتدل بين أعلى وأقل الدرجات(طعيمة: . الع). فالاختبار الذي يأخذ فيه جميع الطلاب صفرا أو مئة أو درجة موحدة ليس اختبارا مميزا وليس

$$
\begin{aligned}
& \text { هو بالاختبار المطلوب(محمد, } 911 \text { (: 1 ( ). } \\
& \text { ز) درجـة الصعوبة }
\end{aligned}
$$

يفيد درجة الصعوبة في إيضاح مدى سهولة أو صعوبة سؤال ما في الاختبار، وهو عبارة عن النسبة المئوية من الطلاب الذين أجابوا عن السؤال إجابة صحيحة ويحسب

بتطبيق المعادلة التالية (Djiwandono, 2008: 212)

$$
\text { r- مكونات اختبار اللغة اختبار عناصر اللغة }
$$

النوع الأول من أنواع اختبارات عناصر اللغة هو اختبار الأصهوات. وأهدافه هي كفاية نظام أصوات اللغة على شكل التعريف والتمييز والنطق والنبر والتنغيم وغيرها. ومن أنواعها اختبار الثنائية الصغرى والتمييز من (Matsna \& Mahyudin, 2012: 88)

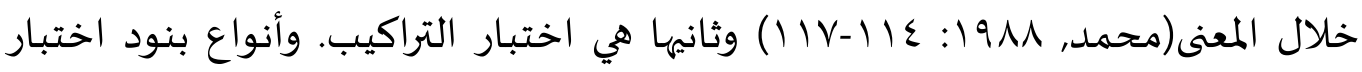
التراكيب هي اختبار التحويل، وصيغة الكلمة. والثالث هو اختبار المفردات، حيث يعتمد في المقام الأول على نوع الاختبار، فإن كان الاختبار اختبارا تصنيفيا أو اختبار كفاية فإنه من الصعوبة بل من الخطأ الاقتصار في اختيار مادتاه على كتاب أو مقرر دراسي معين، إذ إن في ذلك محاباة للدارسين الذين درسوا هذا المقرر. ومن أنواع بنود اختبار المفردات اختبار

$$
\text { التكملة، والمرادف.(محمد, 1911) }
$$

Please cite this article as Muhammad Qodri. (2019). Arabic Language Test in the Perspective of Competency-Based Curriculum for Students of Madrasah Aliyah Negeri 3 Malang. Izdihār : Journal of Arabic Language Teaching, Linguistics, and Literature, 2(2), 115-134. DOI: 


$$
\text { ب) اختبار مهارات اللغة ) اختبار مهارة الاستماع }
$$

اختبار مهارة الاستماع هو الاختبار الذي يتطلب تركيز الطلاب من الجوانب الثلاثة

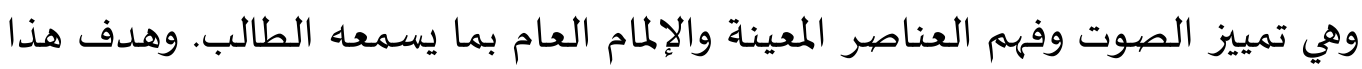

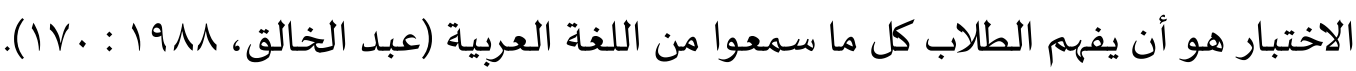
اللغة المسموعة فهيا عناصر صوتية عديدة وعناصر النبر والتنغيم ووضوح النطق ووضوح التمييز السمعي، وهي عناصر تخلو منها اللغة المكتوبة. ولقياس مهارات الاستماع المختلفة، هناك أنواع عديدة من الاختبار منها اختبار الجملة المختلفة واختبار الكلمة المسموعة.

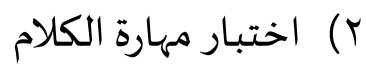

الأهداف من هذا الاختبار هو أن يصل الطالب إلى المستوى المعقول من الطلاقة، أي القدرة على التعبير بشكل مفهوم وسليم دون تردد. وللوصول إلى هذا الهدف ينبغي انتقال الدارس من مرحلة المحاكاة المحضية إلى مرحلة يستطيع فيها التعبير عن أفكاره من خلال التدريب على عناصر اللغة وبصورة خاصهة المفردات والتراكيب والتدريب على استعمال

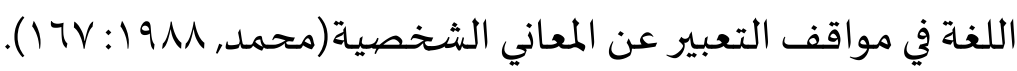
إن درجة الاختبار الكلامي ستكون قريبة من الذاتية بعيدة عن الموضوعية في العديد من الحالات بسبب كثرة العوامل ذات العلاقة. عندما يتكلم الطالب هناك عوامل عديدة جديرة بالمراقبة: النطق والتنغيم والصحة النحوية والمفردات والنبر والوضوح. وهناك عدة أنواع لاختبارات الكلام منها اختبار الإعادة الشفهية واختبار المحاورة.

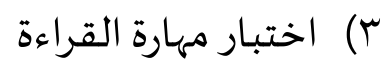

ومن أنواع اختبارات مهارة القراءة هي قراءة اللسان منها قراءة الكلمات، وقراءة الجملة وقراءة النص ومزاوجة الكلمة أو الجملة وغيرها وفهم المقروء منها مزاوجة الجملة

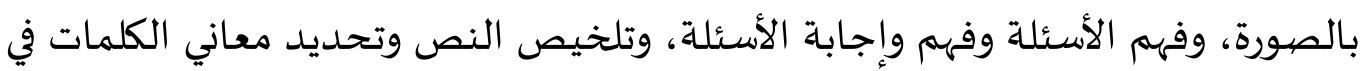

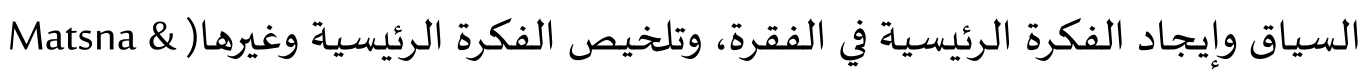
(Mahyudin, 2012: 132 . وتتخذ الأسئلة التي تتلو النص عدة أشكال منها اختبار الاختيار

$$
\begin{aligned}
& \text { من متعدد واختبار ملء الفراغ. } \\
& \text { ع) اختبار مهارة الكتابة }
\end{aligned}
$$


ومن أنواع اختبارات مهارة الكتابة هي كتابة عالية (كتابة الحرف والنقل أو النسخ والإملاء) وإنشاء موجاه (ترتيب الكلمات بالصور، وترتيب الكلمات بالمفردات ووصف الصور وترتيب الجملة لتصبح الفقرة وغيرها) وإنشاء حر (إنشاء المقال وإنشاء المقابلة وإنشاء الفقرة بالموضوع المعين وغيرها(Matsna \& Mahyudin, 2012: 163).

\section{ج- المنهج على أسـاس الكفاءة | - المنهج وعناصره}

المنهج هو كل الخبرات أو الأنشطة، أو الممارسات المخططة والهادفة التي توفرها المدرسة لمساعدة المتعليمن على تحقيق النتاجات التعليمية المنشودة بأفضل ما تستطيعه قدراتهم سواء كان ذلك داخل قاعة الدرس أو خارجها المنهج هو مجموعة من الخبرات والأنشطة التي تقدمها المدرسـة للتلاميذ داخلها وخارجها، بقصد مساعدتهم على النمو الشـامل المتكامل، الذي يؤدي إلى تعديل سلوكهم، ويضمن تفاعلهم مع بيئتهم ومجتمعهم، ويجعلهم يبتكرون حلولا مناسبة لما يوجههم من مشكلات.

أما عناصر أو مكونات المنهج الرئيسي هي الأهداف والمحتوى والخبرات التعليمية والتقويم التي ترتبط ارتباطا وثيقا بعضها ببعض. كما يوضح في نموذج بسيط لعناصر المنهج يرى أن المنهج يتكون من أربعة عناصر هي الأهداف والمحتوى والخبرات التعليمية والتقويم(عميرة.,

r - مفهوم المنهج على أسـاس الكفاءة وخصيائصها

الكفاءة هي مزيج من المعرفة والمهارات والقيم والمواقف التي تعكسها عادة التفكير والتصرف. ويعرف الاختصاص أيضا بالمعرفة والمهارات والقدرات التي يتحكم بها شخص أصبح جزءا مناه، حتى يتمكن من أداء السلوك المعرفي والعاطفي والحركي النفسي قدر الإمكان. شرح جوردون بعض المجالات الواردة في مفهوم الكفاءة على النحو التالي:

المعرفة هي إدراك في المجال المعرفي. على سبيل المثال يعرف المعلم كيفية تحديد احتياجات التعلم وكيفية تعلم الطلاب وفقًا لاحتياجاتهم. 
فهم الأعماق المعرفية والوجدانية للأفراد. على سبيل المثال يجب أن يكون لدى المدرس الذي سيقوم بالتعلم فهم جيد لخصائص وظروف الطلاب حتى يتمكنوا من إجراء التعلم بفعالية وكفاءة.

القدرة هي التي يملكها الفرد للقيام بالمهام والأعمال التي يتم تحميلها عليه. على سبيل المثال قدرة المعلمين على اختيار وتقديم وسائل تعليمية بسيطة لتسهيل التعلم للطلاب. القيمة هي معيار للسلوك تم تصديقه وتكامله نفسيا في الشخص. على سبيل المثال مستوى سلوك المعلم في الأمانة، الانفتاح، التعلم الديمقراطي. المواقف هي المشاعر (سعيدة أو غير سعيدة) أو ردود الفعل على المنهات التي تأتي من

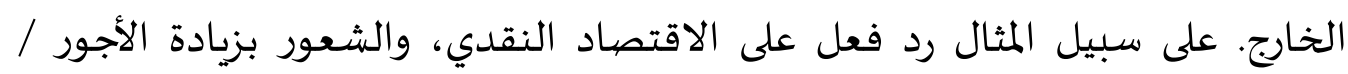

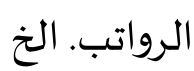
الفائدة هي ميل الشخص للقيام بعمل ما. على سبيل المثال الاهتمام بالتعلم أو القيام بشيء ما. أما خصائص المناهج القائمة على الكفاءة فتشمل على الكفاءة اختيار الكفاءات وفقا لمواصفات مؤشرات التقييم لتحديد نجاح تحقيق الكفاءات وتطوير نظم التعلم. ذكرت وزارة التربية الوطنية أن المناهج القائمة على الكفاءة لها الخصائص التالية (10 : Sanjaya, 2006 ) :

$$
\text { هؤكد على مهارات الكفاءة لكل من الطلاب الفردية والكلاسيكية. }
$$$$
\text { التقديم في التعلم باستخدام أساليب وطرق مختلفة. }
$$

ليست مصادر التعليم معلمين فحسب، ولكن أيضًا موارد تعليمية أخرى تفي بالمتطلبات

$$
\text { التعليمية. }
$$

يؤكد التقييم على العملية ونتائج التعلم في جهود الإتقان أو تحقيق الكفاءة. r- التقويم في المنهج على أساس الكفاءة التقويم في المنهج على أساس الكفاءة هو التقييم على أساس الصفاء هو المناه تنفيذ تقييم يتم تنفيذه بطريقة متكاملة بين تقييم النتائج وعملية التعلم. يتم تقييم نتائج التعلم في تنفيذ المنهج على أساس الكفاءة من خلال(Sanjaya, 2006: 186-187) : 


$$
\text { أ) تقييم الصفف }
$$

يتم إجراء التقييم الطبقي عن طريق الاختبارات اليومية والاختبارات العامة والفحوص الههائية. يتم إجراء الاختبارات اليومية في كل مرة يتم فيها إكمال عملية التعلم في وحدة مناقشـة أو اختصاص معين. يتم إجراء تقييم الفصل من قبل المعلم لمعرفة التقدم ونتائج التعلم للطلاب، وتشخيص صعوبات التعلم ، وتوفير التغذية الراجعة لتحسين عملية

$$
\text { التعلم، وتحديد الزيادة في الرتباة. }
$$$$
\text { ب) اختبار القدرة الأسـاسية }
$$

تجرى اختبارات القدرة الأسـاسية لتحديد القدرة على القراءة والكتابة والعدد اللازمة

$$
\begin{aligned}
& \text { لتحسين برامج التعلم. يتم إجراء اختبارات القدرة الأسـاسية كل عام. } \\
& \text { ج) التقييم النهائي لوحدات التعليم وإصدار الشهادات }
\end{aligned}
$$

في هاية كل فصل دراسي وسنة دراسية، يتم إجراء نشاط تقييم للحصول على صورة كاملة وشـاملة عن اكتمال تعلم الطلاب في وقت معين. لأغراض الشهادة والأداء ونتائج التعلم المدرجة في شهادة إكمال التعلم لا تستند فقط على نتائج التقييم في نهاية المستوى الملدرسي. د) المقارنة يعد قياس الأداء مقياسًا قياسيًا لقياس الأداء والعمليات والنتائج المستمرة لتحقيق ميزة مرضية. يمكن تحديد حجم الشخصية على المستوى المدرسي أو الإقليمي أو الوطني. يتم التقييم على أسـاس مستمر حتى يتمكن الطلاب من الوصهول إلى مرحلة الوحدة من التميز

$$
\begin{aligned}
& \text { في التعله بما يتوافق مع قدرات أعمالهم ومثابرتهم. } \\
& \text { ه) - (تقييم البرنامج }
\end{aligned}
$$

يتم تنفيذ تقييم البرنامج من قبل وزارة التربية الوطنية ومكتب التعليم بشكل

مستمر ومستمر. يتم إجراء تقييم للبرنامج لتحديد مدى ملاءمة المناهج الدراسية مع أسساس ووظيفة وأهداف التعليم الوطني ، فضلاً عن مدى ملاءمته لمتطلبات تنمية المجتمع، وتطور العصر. 


\section{منهج البحث}

هذا البحث من نوع البحث المكتبي على المنهج الوصفي التحليلي بالمدخل الكيفي. ومصادر

البيانات في هذا البحث على شكل وثائق أسئلة اللغة العربية للاختبار النهائي المدرسي في المنهج على أسـاس الكفاءة، فالطريقة التي تم استخدامها في هذا البحث هو طريقة تحليل المضيمون(Benhard, 1954). ويسمى هذا النوع أحيانا ببحوث تحليل المحتوى أو تحليل

$$
\text { الوثائق.(العنيزي \& أخرون, 1999: (V9) }
$$

وقد استخدم الباحث تحليل المضمون الكيفي (Qualitative Content Analysis) وهو كما عرفه حيشيه وشانون Hsieh and Shannon الطريقة التي تهدف إلى التفسير الذاتي للبيانات Hsiieh, E, النصوصية من خلال عملية التصنيف والترميز المنظم مع تحديد المواضيع أو الانماطي \&hannon, 2005: 1278 \& لأن مدخل هذا البحث يندرج تحت المدخل الكيفي، لذلك تكون عملية تحليل البيانات معتمدة على مبادئ هذا المدخل أي يكون هذا التحليل كيفيا. وأما الإجراءات لتحليل البيانات فهي الإجراءات التي قدمها كريفندورف(Krippendorff \& Wajidi, 1980: 69). على أن تحليل المضمون تضمنت خطوات هي قراءة الوثائق، وتقرير الوحدات، وأخذ العينات، والترميز،

$$
\text { وتخفيض البيانات، وتفسير البيانات، والاستنتاج. }
$$

\section{بحث ومناقشة}

بنود أسئلة الاختبار الهائي المدرسي في مادة اللغة العربية لدى طلبة المدرسـة العالية الإسلامية الحكومياة ب مالانج للمنهج على أسـاس الكفاءة، يستند تنظيمها إلى مضمون المنهج وهو الكفاءة المعيارية والكفاءة الأسـاسية من الصف الأول حتى الثالث. وبنود الأسئلة لذا المنهج تشير إلى أن لها بنود العناصر اللغوية وبنود المهارات اللغوية لقياسهما على كفاءة الطلاب في اللغة العربية. لأن من أهداف الاختبار هو قياس تحصيل الطلاب. واشتملت بنود أسئلة الاختبار على العناصر اللغوية وبنود المهارات اللغوية بوصفها إحدى أدوات اختبار اللغة. لأن مكونات اختبار اللغة تتكون

$$
\text { من اختبارات من حيث العناصر اللغوية ومهاراتها. }
$$

من مواصفات الاختبار الجيد هو الصدق، والصدق عبارة عن علاقة بين الاختبار بوصفه مقياسـا والعنصر أو المهاراة المراد قياسها. وصدق الاختبار يعني إلى أي مدى يقيس الاختبار الشيئ الذي وضع من أجله. ولتوفير درجة صدق عالية للاختبار يجب أن يكون المحتوى ذا علاقة بالشيئ 
الذي يراد قياسـا (محمد, 1911 ( 1)) وفي تحليل بنود أسئلة اللغة العربية لاختبار الهائي المدرسي لدى طلبة المدرسة العالية الإسلامية الحكومية ب مالانج، حللها الباحث كيفيا. وهذا التحليل يتعلق بصدق المحتوى، يتطلب صدق المحتوى على تناسب المحتوى بين كفاءة المقيس والاختبار

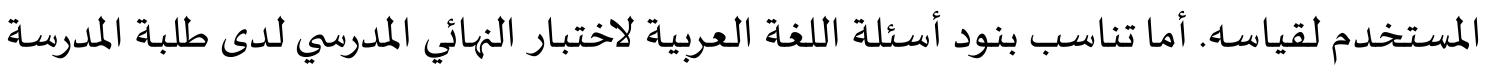

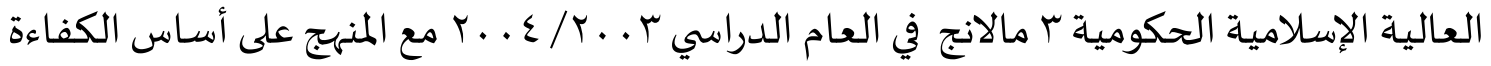

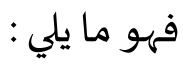

أ- تناسب بنود أسئلة العناصر اللغوية مع المنهج على أساس الكفاءة

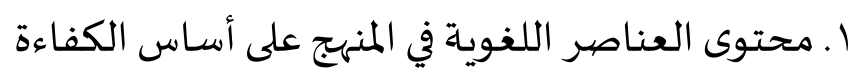

يحتوي المنهج التعليمي KBK لمادة اللغة العربية في المرحلة الثانوية الإسلامية على

كفايات العناصر اللغوية منها المفردات والتراكيب أو القواعد التي تتصور في كل الكفاءة المعيارية Standar Kompetensi في الصف الأول يستوعب الطلاب على فهم ـم مفردة جديدة وفهم التراكيب اللغوية الصحيحة وهي "الاسم والفعل والحرف" و"المذكر والمؤنث" "المفرد والجموع (جمع التكسير،

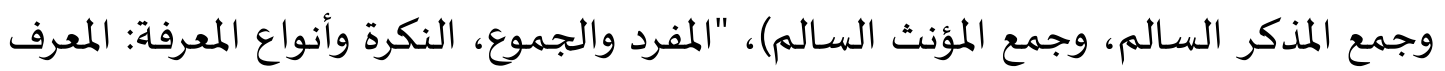
بأل، والضمائر والموصول"، "الفعل الماضي والفعل المضيارع والمصيدر"، "أدوات الجر الكثيرة الورود ومعانها"، "الفعل الماضي والفعل المضارع والمصددر"، و "أدوات الجر الكثيرة الورود المهرد ومعانها"، و"المبتدأ والخبر: المفرد، وشبه الجملة، والجملة الفعلية"، و "المبتدأ والخبر: المفرد، وشباء الجملة، والجملة الفعلية"، "الخبر المقدم".

وفي الصف الثاني يستوعب الطلاب على فهم . ro مفردة جديدة مع حفظ . ro مفردة

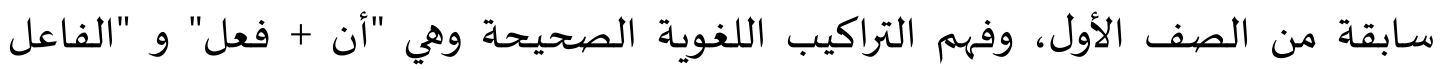

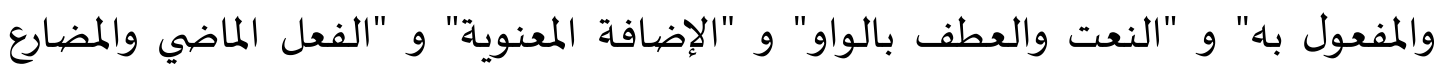
والمصددر للثلاثي المزيد بحرف" و "الفعل الماضي والمضارع والمصددر للثلاثي المزيد بحرفين وبثلاثة أحرف على وزن استفعل" و "الفعل الماضي والمضارع والمصددر للثلاثي المزيد بحرفين وبثلاثة أحرف على وزن استفعل" و "فعل الأمر " و "اسمي الفاعل والمفعول للثلاثي وغير الثلاثي". 
وفي الصف الثالث يستوعب الطلاب على فهم ـ 0 مفردة جديدة مع حفظ . .0 مفردة

سابقة من الصف الأول والثاني، وفهم التراكيب اللغوية الصحيحة وهي "كان-يكون-ليس" و "المرفوعات: المبتدأ والخبر والفاعل والمعطوف على المرفوع" و "المنصيوبات: المفعول به واسم إن وأن وخبر كان المفرد والمعطوف على المنصوب" و "المجرورات: بحروف الجر والإضـافة والنعت" و "الفعل المضارع المنصوب بأن ولام التعليل" و "العدد: المركب والعطف والمائة والألف" و "الفعل المضارع المجزوم بلم ولا الناهية" و "الفعل المضيارع المجزوم بلم ولا الناهية" و "الفعل المبني للمجههول ونائب الفاعل".

من البيان السـابق عرف أن محتوى العناصر اللغوية في المنهج التعليمي KBK للمرحلة

Kompetensi Standar Kompetensi الثانوية قد تصور في الكفاءة المعيارية من الصف الأول حتى الثالث. ويرتكز محتوى العناصر اللغوية للصف الأول على فهم المفردات عددها ـ مب مفردة جديدة وفهم التراكيب اللغوية حسب الموضيوع. أما الصف الثاني

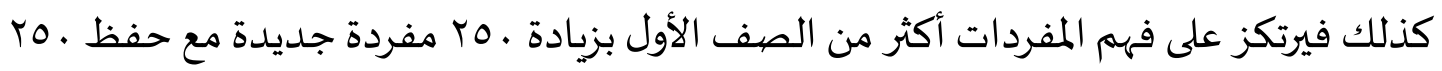
مفردة سابقة في الصف الأول. إذن، على طلاب الصف الثاني من المرحلة الثانوية أن يحفظ . . مفردة مع فهم التراكيب اللغوية الصحيحة المعينة. أما الصف الثالث كذلك فيرتكز على فهم المفردات أكثر من الصف الأول والثاني بزيادة . م مفردة جديدة مع حفظ . م م مفردة سابقة في الصف الأول و . 0r مفردة سابقة في الصف الثاني. وعلى هذا الحال إذن، على طلاب الصف الثالث من المرحلة الثانوية في المنهج التعليمي KBK عليه أن يحفظ . . م مفردة مع فهم التراكيب اللغوية الصحيحة حسب كل الموضوع الموجود في الصف الأول والثاني والثالث. وعلى الرغم من أن المنهج التعليمي KBK قد حمل العناصر اللغوية من بينها المفردات والتراكيب اللغوية فإن هذا المنهج لم يكن لدياه اهتمام في تعليم الأصيوات العربية في مبحث خاص دون أن يشتمل في كل مبحث من المفردات والتراكيب اللغوية. لأن الأصهوات كذلك من العناصر اللغوية المهمة التي هي مادة لإعطاء المعلومات والمفاهيم حول الأصهوات العربية

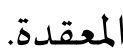

\section{r. بنود أسئلة العناصبر اللغوية}

بنود الأسئلة لمادة اللغة العربية في الاختبار النهائي المدرسي للمنهج التعليمي KBK في

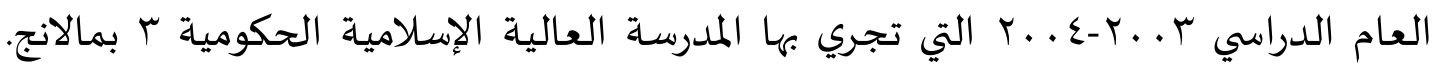


والبنود تتكون من 0؛ سؤالا وهي من نوع الاختبار الاختيار من متعدد. والأجوبة تتكون من أربعة اختيار وهي أ، ب، ج، د. والبنود يحتوي على بنود العناصر اللغوية وهي بنود أسئلة المفردات والتراكيب اللغوية. وبنود أسئلة التراكيب اللغوية هناك أكثر من بنود أسئلة المفردات. بنود أسئلة العناصر اللغوية تحتوي على بنود أسئلة المفردات والتراكيب اللغوية كان عددها هr سؤالا وهي 7 سؤالا لبنود المفردات و 19 سؤالا لبنود التراكيب اللغوية. وكل من بنود أسئلة المفردات والتراكيب في اختبار اللغة العربية النهائي المدرسي يتماشى مع محتوى المنهج لتضيمنه على محتوى المفردات والتراكيب، وأن المنهج KBK يحتوي أيضيا على العناصر اللغوية من المفردات والتراكيب التي تتصور في كل الكفاءة المعيارية والكفاءة الأساسية. وبنود أسئلة العناصر اللغوية في الاختبار النهائي المدرسي في مادة اللغة العربية بالمدرسة

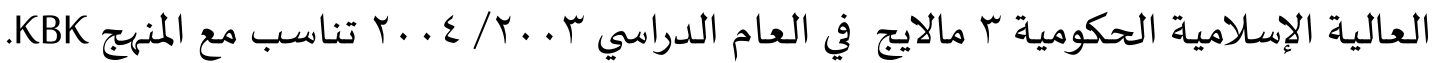
وهذا التناسب دل على صدق المحتوى، حيث تحتوي تلك البنود على العناصر اللغوية وهي بنود أسئلة المفردات وأسئلة التراكيب اللغوية المناسبة بالكفاءة المعيارية والكفاءة الأسـاسية، رغم أن تلك البنود لا تحتوي على بنود أسئلة الأصيوات.

\section{ب- تناسب بنود أسئلة المهارات اللغوية مع المنهج على أسـاس الكفاءة 1- إحتوى المهارات اللغوية في المنهج على أسـاس الكفاءة}

وجد الباحث أن محتوى المهارات اللغوية في المنهج على أسـاس الكفاءة للمدرسـة العالية الإسلامية قد تصور في الكفاءة المعيارية Standar Kompetensi والكفاءة الأساسية Kompetensi Dasar اللغوية على قدر الطلاب في قراءة النصوص وفهمها والتحدث والكتابة من خلال الإنشاء الموجهة حسب الموضوع "من يوميات الطالب" و "كتاب الله الخالد" و "الأعمال الصالحة" و "محمد رسول الله" و "غاية الإيمان" و "العقيدة والعبادات في القرآن" و "الحديث الشريف" و

$$
\text { "نحن المسلمين" باستخدام .0 م مفردة جديدة. }
$$

في الصف الثاني يرتكز محتوى المهارات اللغوية على قدر الطلاب في قراءة النصوص وفهمها والتحدث والكتابة من خلال الإنشاء الموجهة حسب الموضيوع "البطل المسلم" و "أساس 
الإسـلام" و "من حِكَمِ الصهلاة" و "صوم رمضـان" و "الإسلام دين الفطرة" و "الشباب والعمل" و "أبو بكر الصيديق" و "لقمان الحكيم" باستخدام ـ 0 مفردة جديدة.

في الصف الثالث يرتكز محتوى المهارات اللغوية على قدر الطلاب في قراءة النصوص وفهمها والتحدث والكتابة من خلال الإنشاء الموجهة حسب الموضيوع "الإمام الشـافعي" و "رسالة من مكة المكرمة" و "واجب الإنسان نحو ربه" و "المساجد في العصور الأولى" و "مصعب المعلم المجاهد" و "كن في الحياة متفائلا" و "الإسلام والعلم" و "مسجد الاستقلال بجاكرتا" باستخدام

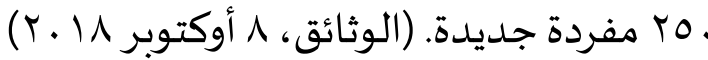

$$
\begin{aligned}
& \text { r-بنود أسئلة المهارات اللغوية }
\end{aligned}
$$

أما بنود أسئلة المهارات اللغوية في الاختبار الههائي المدرسي فتتكون من · ب سؤالا، وكلها لبنود مهارة القراءة. وكل من بنود أسئلة مهارة القراءة في بنود أسئلة الاختبار النهائي المدرسي مناسبة بما يحتوياه المنهج KBK لتضمنها على محتوى المهارات اللغوية في المنهح. لأن المنهج KBK يحتوي مادة اللغة العربية في المدرسة العالية الإسلامية الحكومية ؟ مالانج على كفاءات المهارات اللغوية منها مهارة القراءة التي تتصور في كل الكفاءة المعيارية والكفاءة الأسـاسية غير أن هذه البنود لاتحتوي على بنود أسئلة مهارة الاستماع والكلام والكتابة. بنود أسئلة المهارات اللغوية في الاختبار النهائي المدرسي في مادة اللغة العربية للمدرسـة

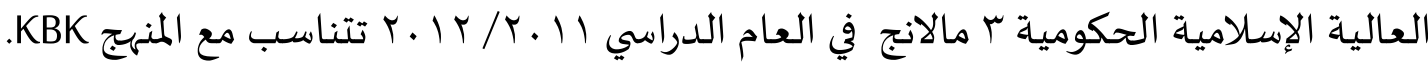
وهذا التناسب دل على صددق المحتوى، بحيث تحتوي تلك البنود على المهارات اللغوية وهي بنود أسئلة مهارة القراءة المناسبة بالكفاءة المعيارية والكفاءة الأسـاسية، رغم أن تلك البنود لا تحتوي على بنود أسئلة مهارة الاستماع والكلام والكتابة.

خاتمة

هناك تناسب بين بنود أسئلة اختبار اللغة العربية الهائي المدرسي لدى طلبة المدرسة

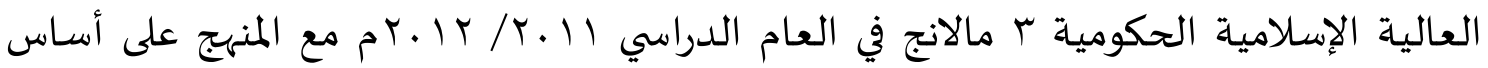
الكفاءة حيث تحتوي على : أ) العناصر اللغوية وهي بنود أسئلة المفردات والتراكيب، والمهارات اللغوية وهي بنود أسئلة مهارة القراءة، كما تناسب البنود الكفاءة المعيارية والكفاءة الأسـاسية، 
رغم أن تلك البنود لا تحتوي على بنود أسئلة الأصيوات في أسئلة العناصر اللغوية وبنود أسئلة مهارة الاستماع والكلام والكتابة في أسئلة المهارات اللغوية.

\section{قائمة المراجع}

Benhard, B. (1954). Content Analysis In Communication Research. Newyork: Hafner.

Djiwandono, S. (2008). Tes Bahasa Pegangan Bagi Pengajar Bahasa. Jakarta: PT. Indeks Anggota IKAPI.

Hsiieh, H.-f., E, S., \& Shannon. (2005). Three Approach to Qualitative Contens Analisys, Journal of Qualitative Health Research. Sage Publications, 15(9).

Krippendorff, K., \& Wajidi, F. (1980). Analisis isi: Pengantar teori dan metodologi: Rajawali Pers.

Matsna, M., \& Mahyudin, E. (2012). Pengembangan Evaluasi dan Tes Bahasa Arab. Tangerang Selatan: Alkitabah.

Sanjaya, W. (2006). Pembelajaran dalam implementasi kurikulum berbasis kompetensi: Kencana.

$$
\begin{aligned}
& \text { الحريري, ر. (1 . . r). التقويم التربوي. عمان: دار المناهج للنشر والتوزيع. } \\
& \text { الطبيب, أ. م. (999 199). التقويم والقياس النفس والتربوي. الإسكندارية: المكتب الجامعي الحديث. } \\
& \text { العمري, ع. ا. (7 ( ا ( ). القياس والتقيم في مجال تعليم العربية للناطقين بغيرها. الرياض: أبحاث } \\
& \text { المؤتمر السنوي العاشر. }
\end{aligned}
$$

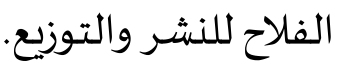
المنصيورة.

Please cite this article as Muhammad Qodri. (2019). Arabic Language Test in the Perspective of Competency-Based Curriculum for Students of Madrasah Aliyah Negeri 3 Malang. Izdihār : Journal of Arabic Language Teaching, Linguistics, and Literature, 2(2), 115-134. DOI: 
عاشور, ر. ق., \& الحوامدة, و. ف. (. • (؟). أساليب تدريس اللغة العربية بين النظرية والتطبيق. عمان: دار المسيرة للنشر والتوزيع.

$$
\begin{aligned}
& \text { عباس, ف. (797 (99). الاختبارات النفسية : تقنياتها إجراءاتها. بيروت: دار الفكر العربي. } \\
& \text { علام, ص. (r . . r). القياس والتقويم التربوي والنفسي. القاهرة: دار الفكر العربي. } \\
& \text { عميرة.، إ. ب. (1991 ). المنهج وعناصره. القاهرة دار المعارف. }
\end{aligned}
$$

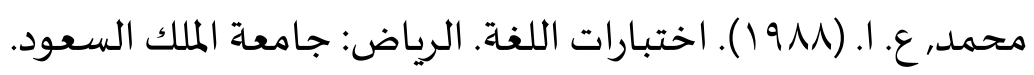

